Pathologe $2021 \cdot 42: 578-590$

https://doi.org/10.1007/s00292-021-00942-9

Angenommen: 3. Februar 2021

Online publiziert: 6. Mai 2021

(c) Der/die Autor(en) 2021

\section{Redaktion}

H. Baba, Essen
Michael Hummel' · Susanna Hegewisch-Becker ${ }^{2}$. Jens Neumann ${ }^{3}$. Arndt Vogel ${ }^{4}$

${ }^{1}$ Institut für Pathologie, Campus Charité Mitte, Charité - Universitätsmedizin Berlin, Berlin, Deutschland ${ }^{2}$ Onkologische Schwerpunktpraxis, Facharztzentrum Eppendorf, Hamburg, Deutschland

${ }^{3}$ Pathologisches Institut, Medizinische Fakultät, Ludwig-Maximilians-Universität München, München, Deutschland

${ }^{4}$ Klinik für Gastroenterologie, Hepatologie und Endokrinologie, Medizinische Hochschule Hannover, Hannover, Deutschland

\title{
BRAF-V600E-Testung beim metastasierten kolorektalen Karzinom und neue, chemotherapiefreie Therapieoptionen
}

Bei Patienten mit einem kolorektalen Karzinom (KRK) ist die BRAF-Testung neben der RAS-Testung fester Bestandteil der leitliniengerechten molekularbiologischen Diagnostik vor Einleitung der Erstlinientherapie. Ziel dieses Artikels ist es, eine aktuelle Übersicht zur Bedeutung von $B R A F$ als prognostischer und prädiktiver Biomarker zu geben, neue Therapieoptionen für KRKPatienten mit BRAF-Mutationen aufzuzeigen sowie die derzeitig einsetzbaren Diagnoseverfahren zur BRAF-Testung darzustellen.

Trotz signifikanter Therapiefortschritte gehört das KRK in Europa weiterhin zu den prognostisch ungünstigsten Krebserkrankungen mit jährlich annähernd 250.000 Todesfällen, die Inzidenz liegt bei über 500.000 Neuerkrankungen [1]. Mit fortschreitender molekularpathologischer Charakterisierung und voranschreitender Klassifizierung des KRK in molekulare Subtypen [2] ergeben sich zunehmend mehr Möglichkeiten zum Einsatz zielgerichteter Therapien, wo-

Die englische Version dieses Beitrages ist unter https://doi.org/10.1007/s00292-021-00946-5 zu finden. durch der molekularen Diagnostik ein immer größerer Stellenwert zukommt.

BRAF-Mutationen kommen bei etwa 8-12\% der Patienten mit einem metastasierten KRK (mKRK) vor [3, 4]. Bei über $95 \%$ aller BRAF-Mutationen handelt es sich um BRAF-V600-Mutationen, bei der in Codon 600 (in Exon 15) des BRAFGens zumeist eine Substitution von Valin durch Glutaminsäure an Position 1799 erfolgt. Neben dieser häufigsten Mutation, $B R A F^{\mathrm{V} 600 \mathrm{E}}$, treten auch seltenere Mutationen in Codon 600 auf, bei der ein Austausch des Valins an Position 600 durch Lysin $\left(B R A F^{\mathrm{V} 600 \mathrm{~K}}\right)$, Asparaginsäure $\left(B R A F^{\mathrm{V} 600 \mathrm{D}}\right)$, Methionin $\left(B R A F^{\mathrm{V} 600 \mathrm{M}}\right)$ oder Arginin $\left(B R A F^{\mathrm{V} 600 \mathrm{R}}\right)$ erfolgt [5]. Klinisch fällt beim Vergleich der BRAFV600-Mutation mit den deutlich selteneren BRAF-Mutationen in den Codons 594 und 596 auf, dass erstere häufiger in rechtsseitigen und muzinösen Primärtumoren mit peritonealer Metastasierung gefunden werden. BRAF ${ }^{594 / 596}$-Tumoren weisen zudem eine günstigere Prognose auf [3]. Die Ausführungen in den nachfolgenden Kapiteln dieser Arbeit beziehen sich immer auf BRAFV600E-Mutationen beim mKRK, soweit nicht explizit anders beschrieben.

B-Raf ist eine Schlüsselkinase im (Ras/RAF/MEK-)MAPK-Signalweg, die in die Regulation des Zellwachstums involviert ist. Die mutationsbedingte Veränderung des BRAF-Gens führt zur konstitutiven Aktivierung dieser Proteinkinase, wodurch unkontrollierte Zellteilung auftritt in deren Folge (Neo-)Angiogenese und Metastasierung zunehmen [6]. Untersuchungen des KRK-Transkriptoms haben zu einer Einteilung des mKRK in 4 Konsensussubtypen („,consensus molecular subtypes“, $\mathrm{CMS}$ ) geführt. KRAS-Mutationen treten überwiegend im epithelialen, „metabolischen" Subtyp CMS3 auf, der sich durch metabolische Dysregulation auszeichnet und auch teilweise chromosomale Instabilität wie auch Mikrosatelliteninstabilität (MSI-H) aufweist [2, 7]. BRAFMutationen hingegen finden sich häufig im MSI-H/Immun-Subtyp CMS1.

$B R A F-$ Mutationen treten nur äußerst selten zusammen mit einer Mutation des RAS-Gens auf, die molekulare Testung auf das Vorliegen dieser Mutationen soll laut aktueller S3-Leitlinie möglichst noch vor Einleitung der Erstlinientherapie erfolgen. Dabei kann die BRAF-Testung am besten gleichzeitig mit dem RASTest oder ggf. auch sequenziell nach Ausschluss der RAS-Mutation erfolgen [3]. 


\section{Onkogene Eigenschaften der BRAF-Mutation}

$B R A F$ ist ein onkogener Treiber bei mKRK-Patienten, der beim malignen Melanom schon lange als therapeutische Zielstruktur etabliert ist. [8]. Die mit einer BRAF-Mutation assoziierten serratierten Adenome des Darms weisen molekulare, morphologische, klinische und epidemiologische Charakteristika auf, die sich von denen der Adenome unterscheiden und die sich im Zuge einer "klassischen Adenom-KarzinomSequenz" basierend auf Mutationen des $A P C$-Gens entwickeln $[9,10]$. Bei der BRAF-getriebenen Ausbildung von „sessilen serratierten Adenomen“ (SSA) kommt es zu Störungen der Apoptose der Kryptenepithelien gefolgt von einer Seneszenz mit epigenetischen Promotor(CpG)-Methylierungen und konsekutiv verminderter Expression verschiedener Gene (zum Beispiel hMLH1, MGMT, p16) $[3,9]$. Bei SSA als Tumorvorstufe und Vorläuferläsionen handelt es sich um flache, kaum aus dem Schleimhautniveau aufragende Polypen, die zumeist im rechtsseitigen Kolon auftreten und auch endoskopisch nur schwer zu erkennen sind $[3,9]$. Patienten mit großen serratierten Adenomen weisen ein erhöhtes Risiko der kolorektalen Karzinomentstehung auf. Bei Frauen mit SSA ist das Risiko gegenüber Männern um den Faktor 5 erhöht [3].

\section{Klar negativer prognostischer Faktor beim KRK}

Beim mKRK gilt erhöhtes Alter ebenso als negativ prognostisches Kennzeichen wie eine Lage des Tumors proximal der linken Flexur [11]. In einer großen retrospektiven Fallserie wurde der Einfluss von BRAF-Mutationen und MSI-H auf die metastatische Ausbreitung und Prognose von mKRK untersucht: BRAFmutante Tumoren und hier wiederum die V600E-Mutation sind gegenüber dem $B R A F$-Wildtyp mit einer signifikant schlechteren Überlebensprognose assoziiert (Median 10,4 versus 34,7 Monate; Hazard Ratio $[\mathrm{HR}]=10,66, p<0,001)$ wie auch mit einer höheren Rate an peritonealen Metastasen und distan- ten Lymphknotenmetastasen [12]. Die prognostisch äußerst negative Auswirkung von $B R A F^{V 600}$ wurde auch bei randomisierten kontrollierten Studien übereinstimmend berichtet $[4,13$, 14]. Eine ausführliche Diskussion des prognostischen Einflusses von BRAFMutationen in Abhängigkeit von der Mikrosatellitenstabilität bzw. -instabilität als weiterem Biomarker findet sich in 2 aktuellen Übersichtsarbeiten [6, 15]. MSI-H tritt, mit Ausnahme des hereditären nicht-Polyposis-assoziierten kolorektalen Karzinoms (HNPCC), mit einer geschätzten Häufigkeit von nur 4-8 $\%$ bei mKRK-Patienten auf [4]. Bei gleichzeitigem Auftreten von BRAF-Mutationen und MSI-H - die Häufigkeit liegt reziprok jeweils bei ungefähr einem Drittel - handelt es sich um sporadische Defekte der DNA-Mismatch-Reparatur (dMMR) [3, 4]. MSI-H-Patienten haben insgesamt eine bessere Prognose als Patienten mit Mikrosatellitenstabilität (MSS)[16]. Trotz insgesamt kleiner Fallzahlen deutet die derzeitig verfügbare klinische Evidenz darauf hin, dass mKRK-Patienten mit einer BRAF ${ }^{V 600 E_{-}}$ Mutation und MSI-H eine insgesamt bessere Prognose haben als Patienten mit einer $B R A F^{V 600 E_{-}}$-Mutation und MSSBefundung, wobei in der metastasierten Situation die Kombination $\mathrm{BRAF}^{\mathrm{V} 600 \mathrm{E}}$ und MSS zu überwiegen und somit die schlechte Prognose der BRAF-Mutation führend zu sein scheint $[6,13,17-20]$.

\section{Prädiktiver Wert bezüglich bisheriger konventioneller Therapien unklar}

Vor dem Hintergrund eines sich mutuell nahezu ausschließenden Auftretens von $B R A F$ - und RAS-Mutationen [21] und der nachgewiesen negativen prädiktiven Bedeutung von RAS-Mutationen für den Einsatz von Anti-EGFR-Therapien stellt sich auch für $B R A F-$ Mutationen die Frage der prädiktiven Relevanz bezüglich des Einsatzes der beiden monoklonalen Antikörper Cetuximab und Panitumumab. Beide sind beim KRK ausschließlich für den Einsatz bei Patienten mit RAS-Wildtyp zugelassen. Für den Einsatz von Anti-EGFR-Therapien bei Patienten mit einer BRAF-Mutation liegen nur begrenzte
Daten aus Subgruppenanalysen größerer konfirmatorischer Studien (• Tab. 1) sowie rein retrospektive, aus klinischen Praxisdaten erhobene Fallserien vor [22, 23].

Einen klinischen Benefit haben 2 sich in Teilen überlappende Metaanalysen dieser Daten der Anti-EGFRAntikörpertherapie bei RAS-plus BRAFWildtyp-Patienten bestätigen können. Bei RAS-Wildtyp Patienten mit einer BRAF-Mutation zeigten sich in der Gesamtheit der Daten allerdings nur bedingte, nicht signifikante klinische Vorteile beim progressionsfreien Überleben wie auch beim Gesamtüberleben $[24,25]$. Die derzeitige Datenlage wird auch in dem Sinne kontrovers diskutiert, dass diese Daten eine Exklusion von Anti-EGFR-Antikörpern für die Patientengruppe mit $B R A F^{V 600 E}$-Mutation gleichfalls nicht rechtfertigen. Die Daten aus der deutschen, randomisierten Phase-II-Studie VOLFI zum Vergleich von Panitumumab plus Chemotherapie versus alleiniger Chemotherapie in der Erstlinie zeigten, dass die Hinzugabe von Panitumumab zur Chemotherapie die Ansprechrate (ORR) bei den 14 Patienten mit $B R A F^{V 600 E}$-mutierten Tumoren tendenziell erhöhte (Odds Ratio 14,93; 95\%-KI 1,03-200,00) [26].

Für die im klinischen Alltag des mKRK bedeutsame und unabhängig vom RAS-Status einsetzbare Anti-VEGFTherapie - wie die Anti-EGFR-Therapie in Kombination mit (in der Erstlinie zumeist) Oxaliplatin-haltiger beziehungsweise (in der Zweitlinie zumeist) Irinotecan-haltiger Chemotherapie gegeben - stehen bisher keine bzw. nur indirekte Vergleiche zur Verfügung, sodass der prädiktive Wert einer BRAFTestung hier unklar ist. Die Ergebnisse einer kleinen Phase-II [27] sowie Subgruppenanalysen zweier großer PhaseIII-Studien $[28,29]$ lassen in der Gesamtschau keine eindeutige Beurteilung der Bedeutung einer intensivierten Chemotherapie (FOLFOXIRI) bei BRAFmutierten Patienten zu. Eine Metaanalyse von 5 randomisierten Studien mit heterogenen Fallzahlen $(n=70-679)$ und unterschiedlichen Fragestellungen kam jüngst zu dem Ergebnis, dass bei BRAF-mutierten Patienten - bei wei- 
Pathologe 2021 · 42:578-590 https://doi.org/10.1007/s00292-021-00942-9

(c) Der/die Autor(en) 2021

\section{Hummel · S. Hegewisch-Becker · J. Neumann · A. Vogel}

\section{BRAF-V600E-Testung beim metastasierten kolorektalen Karzinom und neue, chemotherapiefreie Therapieoptionen}

\section{Zusammenfassung}

Die Therapie des metastasierten kolorektalen Karzinoms (mKRK) hat in den letzten 25 Jahren tief greifende Veränderungen erfahren. Auf die Zulassung neuerer Chemotherapeutika folgten ab 2005 die ersten zielgerichteten Therapien, die sich gegen den epidermalen Wachstumsfaktorrezeptor (EGFR) bzw. gegen Rezeptoren vaskulärer endothelialer Wachstumsfaktoren (VEGFR) richteten. Mit der fortschreitenden molekularen Charakterisierung des $m K R K$ in den letzten 10 Jahren und der Einteilung der Erkrankung in 4 KonsensusSubtypen zeichnet sich weiterer Wandel ab, unter anderem durch Einführung speziell entwickelter Proteinkinaseinhibitoren wie auch Immuncheckpoint-Inhibitoren in den Therapiealgorithmus.
Eine angepasste molekularpathologische Testung ist heute für eine leitliniengerechte Behandlung von mKRK-Patienten unabdingbar. Neben der RAS-Testung als Voraussetzung für die Therapieentscheidung bezüglich Cetuximab und Panitumumab ist die BRAFTestung äußerst relevant, um - im Falle des Nachweises einer BRAF-V600E-Mutation - eine Therapieentscheidung zugunsten der neu zugelassenen, chemotherapiefreien Kombination aus dem BRAF-Inhibitor Encorafenib und Cetuximab treffen zu können. Eine erweiterte Diagnostik sollte auch die Genominstabilität (Mikrosatelliten-Instabilität) einbeziehen. Insgesamt müssen immer mehr molekulare Alterationen simultan untersucht werden, sodass sich zunehmend die Verwendung des fokussierten Next Generation Sequencing empfiehlt.

Diese Übersichtsarbeit beschreibt die prognostische Relevanz der BRAF-Testung im Rahmen der molekularpathologischen Diagnostik des mKRK, stellt neue Therapieoptionen zur Behandlung BRAF-mutierter mKRKPatienten vor und erläutert, welche modernen DNA-analytischen und immunohistochemischen Verfahren zur BRAF-Diagnostik von mKRK-Patienten zur Verfügung stehen.

\section{Schlüsselwörter}

Cetuximab - Encorafenib - EGFR-Inhibitoren · Proteinkinaseinhibitoren . Protoonkogene B-Raf-Proteine

\section{BRAF-V600E testing in metastatic colorectal cancer and new, chemotherapy-free therapy options. German version}

\section{Abstract}

In the past 25 years, treatment of metastatic colorectal cancer (mCRC) has undergone profound changes. The approval of newer chemotherapeutics such as irinotecan and oxaliplatin was followed in 2005 by the first targeted therapies, for example, monoclonal antibodies directed against the epidermal growth factor receptor (EGFR), as cetuximab and panitumumab, or the angiogenesis inhibitors bevacizumab, ramucirumab, and aflibercept. With the rapidly progressing molecular characterization of $\mathrm{mCRC}$ in the last 10 years and the classification of the disease in four consensus subtypes, further changes are emerging, which will promote, among other things, the introduction of protein-kinase inhibitors developed for specific molecular aberrations as well as immune checkpoint inhibitors into the treatment algorithm. Thorough molecular pathologic testing is indispensable today for guideline-compliant treatment of $\mathrm{mCRC}$ patients. In addition to RAS testing as a precondition for the therapy decision with regard to cetuximab and panitumumab, BRAF testing is of considerable relevance to allow decision making with regard to the newly approved chemotherapyfree combination of the BRAF inhibitor encorafenib and cetuximab in cases where a BRAF-V600E mutation is detected. Additional diagnostic tests should also include genome instability (microsatellite instability). Overall, more and more molecular alterations need to be investigated simultaneously, so that the use of focused next-generation sequencing is increasingly recommended.

This overview describes the prognostic relevance of $B R A F$ testing in the context of molecular pathologic diagnostics of $\mathrm{mCRC}$, presents new treatment options for BRAF-mutated mCRC patients, and explains which modern DNA analytical and immunohistochemical methods are available to detect $B R A F$ mutations in $\mathrm{mCRC}$ patients.

Keywords

Cetuximab · Encorafenib · BRAF-inhibitors Protein kinase inhibitors - Proto-oncogene proteins B-raf terhin insgesamt kleinen Fallzahlen in der Erstlinie eher kein gesteigerter Nutzen durch die intensivierte Kombinationstherapie besteht [30]. Eine im Herbst 2020 vorgestellte Metaanalyse der ARCAD-Studiengruppe mit gepoolten Daten zweier Studien, die den Ansatz Chemotherapie plus Anti-EGFR- bzw. plus Anti-VEGF-Therapie in der Erstlinientherapie des $\mathrm{mKRK}$ direkt verglichen, konnte für die Subgruppe der BRAF- mutierten Patienten $(n=138)$ keinen relevanten Unterschied im Gesamtüberleben aufzeigen zwischen Bevacizumabbasierter Behandlung und Cetuximabbasierter Therapie $(\mathrm{HR}=1,01,95 \%$-KI 0,69-1,48) [31]. Der Wert der AntiVEGF-Therapie mit Bevacizumab an sich wie auch die prädiktive Rolle von BRAF für die Einleitung einer Bevacizumab-basierten Therapie erfordern noch weitergehende Untersuchungen (- Tab. 1).

Obwohl zielgerichtete Tyrosinkinaseinhibitoren in der klinischen Routine seit 2011 mit viel Erfolg beim $B R A F^{V 600}$ mutierten Melanom eingesetzt werden, zeigte sich das BRAF-mutierte mKRK wenig sensitiv bei monotherapeutischem Einsatz [32, 33]. Die Ursache hierfür scheinen KRK-spezifische Resistenzmechanismen in der MAPK-Signalkaskade 
Tab. 1 Studien und retrospektive Analysen zur Wertigkeit von BRAFals prädiktiver Marker beim Einsatz von Anti-EGFR-Therapien (A) bzW. Anti-VEGFTherapien (B) beim BRAF-mutierten metatstasierten kolorektalen Karzinom (mKRK)

\begin{tabular}{|c|c|c|c|c|c|c|c|c|}
\hline $\begin{array}{l}\text { Studie/Phase } \\
\text { (bzw. Typ) } \\
\text { Studie }\end{array}$ & Vergleich & $\begin{array}{l}\text { "Backbone" } \\
\text { (Therapie) }\end{array}$ & $\begin{array}{l}N_{\text {ITT, total }} \\
\text { [N } N_{\text {BRAF-mut. }} \\
\text { (soweit } \\
\text { ermittelt) }\end{array}$ & $\begin{array}{l}\text { BRAF- } \\
\text { Assessment } \\
\text { (diagnost. Me- } \\
\text { thode) }\end{array}$ & $\begin{array}{l}\text { OS } \\
\text { (Mo- } \\
\text { nate) }\end{array}$ & $\begin{array}{l}\text { PFS } \\
\text { (Mo- } \\
\text { nate) }\end{array}$ & $\begin{array}{l}\text { ORR } \\
\text { (\%) }\end{array}$ & HR [95\%KI] \\
\hline
\end{tabular}

\begin{tabular}{|c|c|c|c|c|c|c|c|c|c|}
\hline \multicolumn{10}{|c|}{ Anti-EGFR-Therapien } \\
\hline \multicolumn{10}{|c|}{ Erstlinientherapie } \\
\hline $\begin{array}{l}\text { Crystal + } \\
\text { OPUS/III (R- } \\
\text { SGA) }\end{array}$ & $\begin{array}{l}\text { Cetuximab + CTx vs. } \\
\text { CTx }\end{array}$ & $\begin{array}{l}\text { FOLFIRI (Crys- } \\
\text { tal), FOLFOX4 } \\
\text { (OPUS) }\end{array}$ & 1535 [32 vs. 38] & PNA-clamping PC & $\begin{array}{l}14,1 \text { vs. } \\
9,9\end{array}$ & $\begin{array}{l}7,1 \text { vs. } \\
3,7\end{array}$ & $\begin{array}{l}22 \\
\text { vs. } \\
13\end{array}$ & $\begin{array}{l}\text { OS: } 0,62[0,36-1,06] \\
\text { PFS: } 0,67 \\
{[0,34-1,29]}\end{array}$ & $\begin{array}{l}\text { Bokemeyer } \\
\text { et al. [36] }\end{array}$ \\
\hline $\begin{array}{l}\text { PRIME/III (R- } \\
\text { SGA) }\end{array}$ & $\begin{array}{l}\text { Panitumumab + CTx } \\
\text { vs. CTx }\end{array}$ & FOLFOX & 1183 [24 vs. 29] & PNA-clamping PC & $\begin{array}{l}10,5 \text { vs. } \\
9,2\end{array}$ & $\begin{array}{l}6,1 \text { vs. } \\
5,4\end{array}$ & NA & $\begin{array}{l}\text { OS: } 0,90[0,46-1,76] \\
\text { PFS: } 0,58 \\
{[0,29-1,15]}\end{array}$ & $\begin{array}{l}\text { Douillard } \\
\text { et al. [37] }\end{array}$ \\
\hline $\begin{array}{l}\text { FIRE-3/III (R- } \\
\text { SGA) }\end{array}$ & $\begin{array}{l}\text { Cetuximab + CTx vs. } \\
\text { Bevacizumab + CTx }\end{array}$ & FOLFIRI & $752[23$ vs. 25$]$ & Pyrosequencing & $\begin{array}{l}12,3 \text { vs. } \\
13,7\end{array}$ & $\begin{array}{l}6,6 \text { vs. } \\
6,6\end{array}$ & $\begin{array}{l}52 \\
v s . \\
40\end{array}$ & $\begin{array}{l}\text { OS: } 0,79[0,43-1,46] \\
\text { PFS: } 0,84 \\
{[0,47-1,51]}\end{array}$ & $\begin{array}{l}\text { Stintzing } \\
\text { et al. [38] }\end{array}$ \\
\hline \multicolumn{10}{|c|}{ Zweitlinientherapie } \\
\hline $\begin{array}{l}\text { 20020181/III } \\
\text { (R-SGA) }\end{array}$ & $\begin{array}{l}\text { Panitumumab + CTx } \\
\text { vs. CTx }\end{array}$ & FOLFIRI & 1186 [22 vs. 23] & PCR/Sanger & $\begin{array}{l}5,7 \text { vs. } \\
4,7\end{array}$ & $\begin{array}{l}2,5 \text { vs. } \\
1,8\end{array}$ & NA & NA & $\begin{array}{l}\text { Peeters } \\
\text { et al. [39] }\end{array}$ \\
\hline $\begin{array}{l}\text { PICCOLO/III (R- } \\
\text { SGA) }\end{array}$ & $\begin{array}{l}\text { Panitumumab + CTx } \\
\text { vs. BSC }\end{array}$ & Irinotecan & $460[37$ vs. 31$]$ & $\begin{array}{l}\text { PCR/ } \\
\text { Pyrosequencing }\end{array}$ & NA & NA & $\begin{array}{l}11 \\
\text { vs. } 6\end{array}$ & NA & $\begin{array}{l}\text { Seymour } \\
\text { et al. [40] }\end{array}$ \\
\hline \multicolumn{10}{|c|}{ Therapierefraktäre Patienten ( $\geq 2$ Vortherapien) } \\
\hline $\begin{array}{l}20020408 / I I I \\
\text { (R-SGA) }\end{array}$ & $\begin{array}{l}\text { Panitumumabvs. } \\
\text { BSC }\end{array}$ & $\varnothing$ & $463[18 \mathrm{c}]$ & $\begin{array}{l}\text { PCR (Sequenzie- } \\
\text { rung) }\end{array}$ & NA & NA & $\begin{array}{l}0 \text { (vs. } \\
0)\end{array}$ & $\begin{array}{l}\text { NA } \\
\text { PFS: } 0,34 \\
{[0,09-1,24]}\end{array}$ & $\begin{array}{l}\text { Peeters } \\
\text { et al. [41] }\end{array}$ \\
\hline $\begin{array}{l}\text { CO.17/III (R- } \\
\text { SGA) }\end{array}$ & Cetuximab vs. BSC & $\varnothing$ & $572[4$ vs. 6$]$ & $\begin{array}{l}\text { PCR (Sequenzie- } \\
\text { rung) }\end{array}$ & $\begin{array}{l}1,8 \text { vs. } \\
3,0\end{array}$ & NA & $\begin{array}{l}0 \text { vs. } \\
0\end{array}$ & $\begin{array}{l}\text { OS: } 0,84 \text { [NA-NA] } \\
\text { PFS: } 0,76 \text { [NA-NA] }\end{array}$ & $\begin{array}{l}\text { Karapetis } \\
\text { et al. [42] }\end{array}$ \\
\hline \multicolumn{10}{|c|}{ Anti-VEGF-Therapien } \\
\hline \multicolumn{10}{|c|}{ Erstlinientherapie } \\
\hline $\begin{array}{l}\text { TRIBE/III (R- } \\
\text { SGA) }\end{array}$ & $\begin{array}{l}\text { Bevacizumab; Vgl. } \\
\text { zweier CTx-Back- } \\
\text { bones }\end{array}$ & $\begin{array}{l}\text { FOLFOXIRI vs. } \\
\text { FOLFIRI }\end{array}$ & $508[16$ vs. 12] & Pyrosequencing & $\begin{array}{l}19,0 \text { vs. } \\
10,7\end{array}$ & $\begin{array}{l}7,5 \text { vs. } \\
5,5\end{array}$ & $\begin{array}{l}56 \\
v s . \\
42\end{array}$ & $\begin{array}{l}\text { OS: } 0,54[0,24-1,20] \\
\text { PFS: } 0,57 \\
{[0,27-1,23]}\end{array}$ & $\begin{array}{l}\text { Cremolini } \\
\text { et al. [28] }\end{array}$ \\
\hline $\begin{array}{l}\text { Loupakis } \\
\text { et al./II }\end{array}$ & Bevacizumab + CTx & FOLFOXIRI & $25\left[25^{\mathrm{d}}\right]$ & $\begin{array}{l}\text { HRM-Analyse/ } \\
\text { Sequenzierung }\end{array}$ & 24,1 & 9,2 & 60 & NA & $\begin{array}{l}\text { Loupakis } \\
\text { et al. [27] }\end{array}$ \\
\hline \multicolumn{10}{|c|}{ 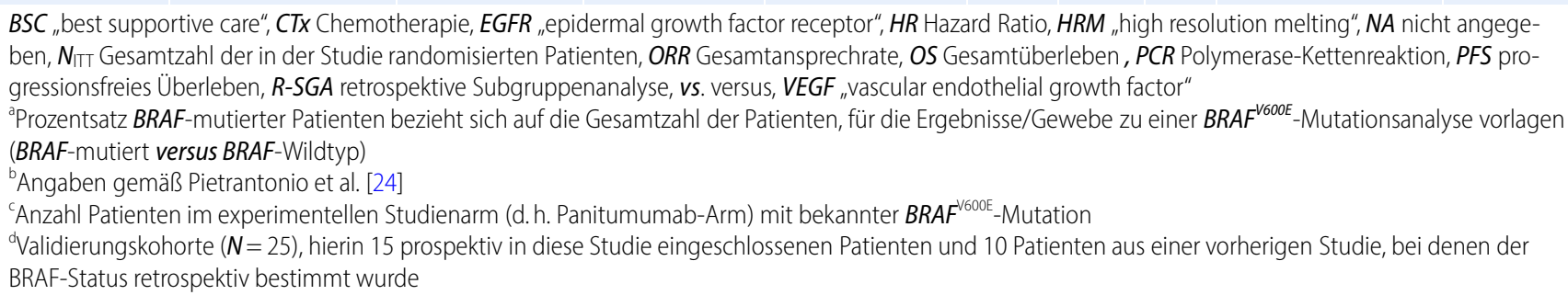 } \\
\hline
\end{tabular}

zu sein. In-vitro-Studien belegten eine Unterdrückung des zwischen der ERKKinase und dem EGFR bestehenden negativen Feedbackloops unter BRAF-Monotherapie bei insgesamt hoher EGFRExpression und möglicherweise stärkerer Aktivierung des Rezeptors durch seine Liganden (• Abb. 1; [33, 34]). Dies resultiert in einer Reaktivierung des EGFRSignalwegs, z. B. unter Umgehung des mutierten BRAF-Proteins über CRAF. Die zusätzliche Inhibierung des EGFRSignalwegs durch gleichzeitige Gabe ei- ner gegen EGFR-gerichteten Therapie zusätzlich zur BRAF-Blockade erscheint daher wichtig, um die mehrgleisigen Resistenzmechanismen innerhalb des MAPK-Signalwegs zu blockieren [33, 35].

\section{Therapieoptionen beim BRAF- mutierten mKRK}

Die Therapie des mKRK ist bisher in der Erst- wie Zweitlinie generell durch Verwendung von Kombinationschemothe- rapien geprägt und, wie im Kapitel zuvor dargestellt, zumeist - bei linksseitigen RAS-Wildtyp-Tumoren - in Verbindung mit einer EGFR-Antikörpertherapie $[3,4]^{1}$. Die gültigen Therapieempfehlungen beim mKRK räumen dem All-

1 Bezüglich der Leitlinien der European Society of Medical Oncology (ESMO) gibt es neben den seit 2016 zuletzt neu publizierten "Consensus Guidelines" für das metastasierte KRK (siehe Ref.[4]) die Anfang 2018 publizierten „Pan-Asian Adapted ESMO Consensus Guidelines". Auch wenn in diesem Artikel auf die etwas ältere 


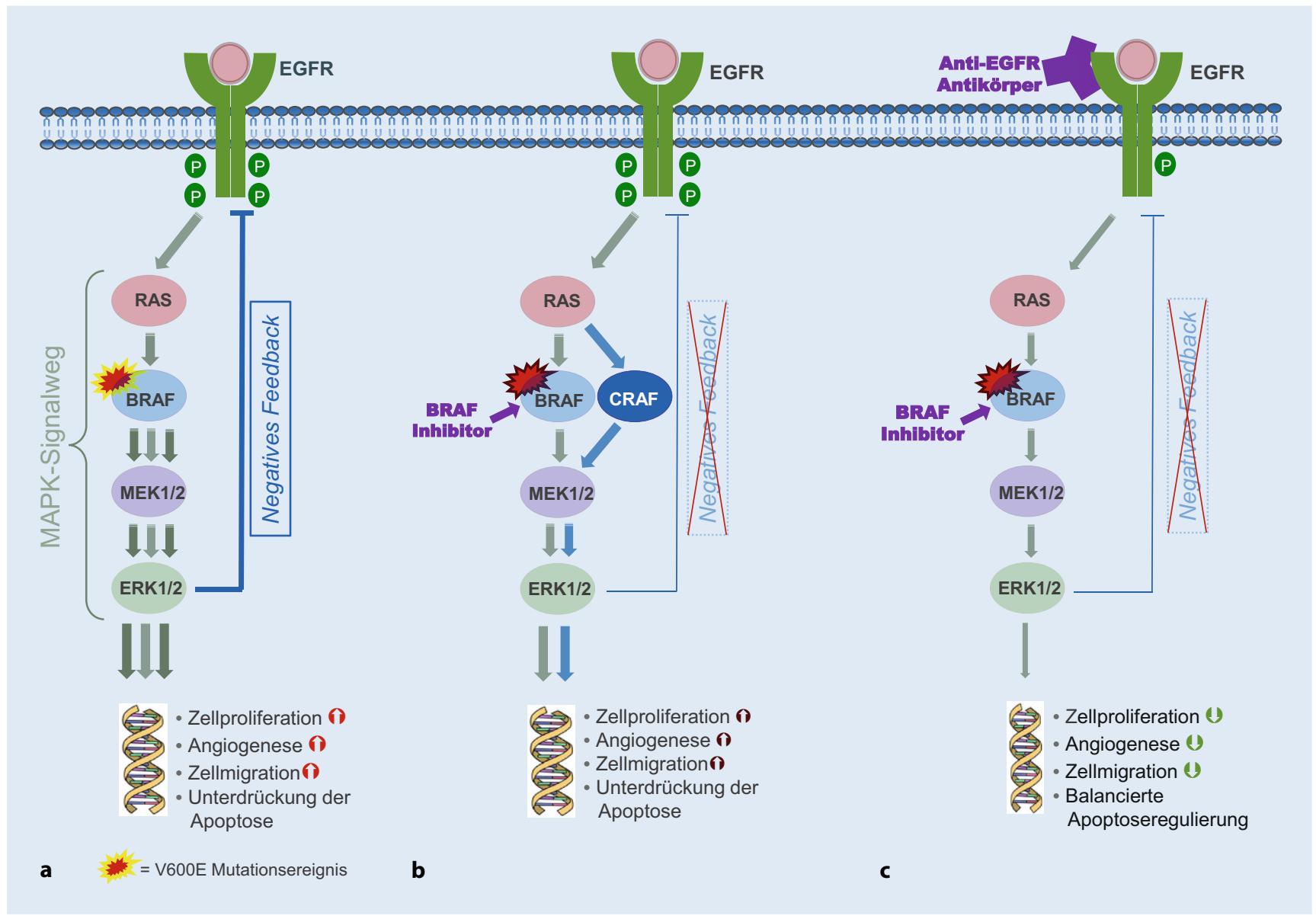

Abb. 1 \ Der MAPK-Signalweg. a Signalverstärkung bei Vorliegen einer aktivierenden BRAF-Mutation. b Inhibition des durch Mutation aktivierten $B R A F$ mit resultierender Unterdrückung des ERK-vermittelten negativen Feedbackloops und einer Reaktivierung des MAPK-Signalweges über CRAF. c Vermeidung von Resistenzmechanismen: Wirkmechanismus der kombinierten BRAF- und EGFR-Blockade. BRAF "rapidly accelerated fibrosarcoma isoform B", $C R A F_{\text {" }}$ rapidly accelerated fibrosarco-

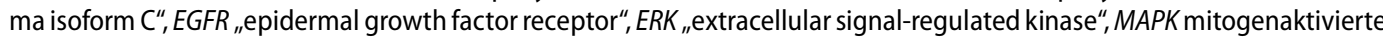
Proteinkinase, MEK MAPK/ERK-Kinase, RAS Rat-sarcoma-Protoonkogen. (Abbildung modifiziert nach Taieb et al. [15], CC BYLizenz)

gemeinzustand der häufig älteren Patienten hinsichtlich der Therapieentscheidung großen Raum ein und unterscheiden - bei den Patienten, die fit genug für eine systemische Therapie sind - zwischen den Behandlungszielen „Zytoreduktion", mit dem Ziel einer Reduktion der Tumormasse, sowie „Krankheitskontrolle“ mit dem Ziel des Herauszögerns weiterer Progression.

ESMO Guideline referenziert wird, gilt der Bezug immer für beide Guidelines und die darin abgebildete aktuelle Studienevidenz.

\section{Erstlinientherapie beim BRAF- mutierten mKRK}

Die Kombination eines Antimetaboliten (5-Fluorouracil plus Leucovorin als Folinsäurederivat) mit einer die DNAReplikation störenden Platinverbindung (Oxaliplatin) sowie einem Topoisomerase-I-Inhibitor (Irinotecan) und dem Angiogenesehemmer (anti-VEGF) Bevacizumab in BRAF-mutierten mKRKPatienten mit gutem Allgemeinzustand ist derzeit europäischer Leitlinienstandard für diese Subentität [4]. Hinsichtlich der Evidenzniveaus in der BRAFmutierten Subgruppe ist allerdings zu beachten, dass die Leitlinienempfehlung nur auf einer sehr geringen Patientenzahl $(N=28)$ aus der TRIBE-Studie beruht und somit mit entsprechenden Unsicherheiten behaftet ist [28]. In der BRAF-Subgruppe dieser Phase-III-Studie betrug das Gesamtüberleben unter FOLFOXIRI plus Bevacizumab 19 Monate, $56 \%$ der Patienten sprachen auf die Therapie an. Jedoch wurde kein signifikanter Unterschied gegenüber der Vergleichstherapie aus FOLFIRI plus Bevacizumab erreicht (•Tab. 1; [28]). Dieser Erstlinienstandard ist momentan Gegenstand kontroverser Diskussion. Eine kürzlich publizierte Metaanalyse aus 5 randomisierten Studien zu FOLFOXIRI plus Bevacizumab vs. Doublet-Chemotherapie plus Bevacizumab ergab bei BRAF-mutierten Tumoren einen nicht signifikanten Trend zugunsten des we- 


\section{Phase III (vorbehandeltes, BRAF-mut. mKRK): Studiendesign / Outcomes BEACONCRC}
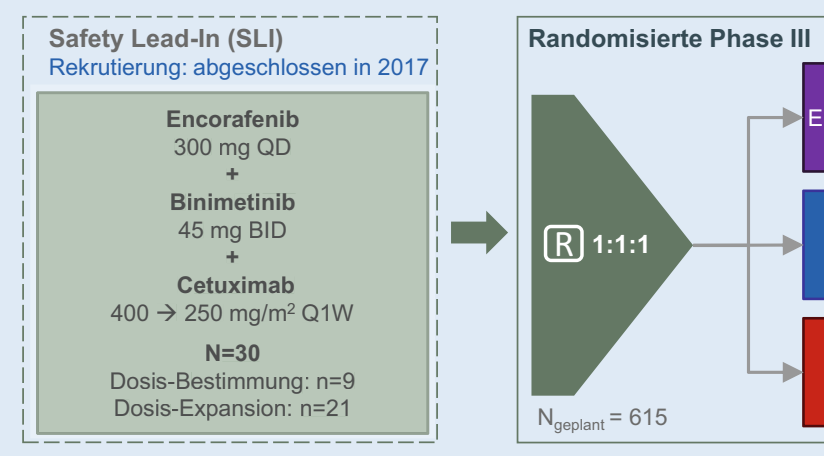

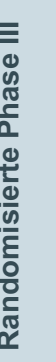

Primäre Endpunkte

- OS: Dreifachblockade vs. Kontrolle

ORR: Dreifachblockade vs. Kontrolle

Sekundärer Hauptendpunkt

OS: Zweifachblockade vs. Kontrolle

Weitere sekundäre \& explorative Endpunkte

- ORR: Zweifachblockade vs. Kontrolle\#

PFS: Dreifachblockade vs. Kontrolle\#

PFS: Zweifachblockade vs. Kontrolle\#

OS: Dreifach- vs. Zweifachblockade*

Lebensqualität

Sicherheit und Verträglichkeit

- PK, BM, genomische/proteomische Analysen

\# a-Kontrolle per Testhierarchie

* Vergleich statistisch nicht gepowert

\$ klinische UE, keine Darstellung von Laborwertabweichungen
$\Rightarrow$ Outcomes Primäre Endpunkte (Update-Analyse; medianes Follow-Up 12,8 Monate [44])

- Medianes OS: 9,3 vs. 5,9 Monate (HR [95\%KI]: 0,61 [0,48-0,77])

ORR [95\%KI]: $27 \%[21-33]$ vs. $2 \%[<1-5]$

$\Rightarrow$ Outcomes Hauptsekundärer Endpunkt (Update-Analyse [44])

- Medianes OS: 9,3 vs. 5,9 Monate (HR [95\%KI]: 0,60 [0,47-0,75])

$\Rightarrow$ Outcomes Sekundäre \& explorative Endpunkte (Update-Analyse [44])

- ORR [95\%KI]: $20 \%[15-25]$ vs. $2 \%[<1-5]$

Medianes PFS: 4,5 vs. 1,5 Monate (HR [95\%KI]: 0,42 [0,33-0,53])

- Medianes PFS: 4,3 vs. 1,5 Monate (HR [95\%KI]: 0,44 [0,35-0,55])

- Medianes OS: 9,3 vs. 9,3 Monate (HR [95\%KI]: 0,95 [0,74-1,21])

$\Rightarrow$ Outcomes Unerwünschte Ereignisse $\$$ (UE) alle Grad / $\geq$ Grad 3 (UE häufiger 5\% [43])

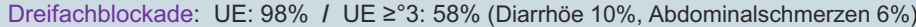

Zweifachblockade: UE: $98 \%$ I UE $\geq 03: 50 \%$

Kontrolle: UE: $97 \%$ / UE $\geq^{\circ} 3: 61 \%$ (Diarrhöe $10 \%$ )

Abb. 2 A Design der Phase-III-Studie BEACONCRC bei Patienten mit einem vorbehandeltem metastasierten kolerektalen Karzinom (mKRK) und BRAF ${ }^{V 600 E}$-Mutation. BID zweimal täglich, BM Biomarker, FOLFIRI Folsäure + Fluoruracil + Irinotecan, HR Hazard Ratio, ORR Gesamtansprechrate, OS Gesamtüberleben, PD Progression, PFS progressionsfreies Überleben, PK Pharmakokinetik, Q1W wöchentlich, QD einmal täglich, $R$ Randomisierung, ${ }^{\circ} \mathrm{Grad}$

niger intensiven Regimes $(n=115$; HR: 1,12, $95 \%$-KI: 0, 75-1,68) [30].

Aufgrund der schlechten Prognose von mKRK-Patienten mit einer $B R A F^{V 600 E}$-Mutation kommt dem Konzept, die Erstlinienbehandlung beim mKRK möglichst aggressiv unter Verwendung fast des gesamten Arsenals an Therapiemodalitäten anzugehen, auf Basis der aktuellen Empfehlungen klinische Bedeutung $\mathrm{zu}$ - insbesondere, wenn eine Zytoreduktion angestrebt wird. Allerdings ist unklar, in welchem Umfang in Deutschland Patienten diese intensivierte und mit entsprechenden Nebenwirkungen behaftete Erstlinientherapie erhalten.

Wie zuvor geschildert ist darüber hinaus die Frage des Einsatzes der chemotherapiekombinierten Anti-EGFRTherapie bei BRAF-mutierten Tumoren auf Basis der nicht eindeutigen Ergebnisse zweier Metaanalysen ebenfalls
Gegenstand einer kontroversen Debatte $[24,25]$.

\section{Neue chemotherapiefreie,} zielgerichtete Optionen in der Zweit- bzw. Drittlinientherapie

Aufgrund der bis dato limitierten Therapieoptionen nach erfolgter Erstlinientherapie konnten sich in den Leitlinien für die Zweit-/Drittlinientherapie des BRAFmutierten mKRK bislang keine klaren Empfehlungen herausbilden [3, 4]. Die deutsche S3-Leitlinie von 2019 schrieb hierzu: „individuelle (derzeitig) nicht zugelassene Therapieansätze, z. B. mit einem BRAF-inhibitor, MEK-Inhibitor und Anti-EGFR-Antikörper oder wenn möglich die Behandlung im Rahmen einer klinischen Studie (sind) in Betracht zu ziehen"; wobei die hier genannten Therapieoptionen bislang keine Zulassung für diese Indikation besaßen.
Mit der im Juni 2020 erfolgten EUZulassung der Kombinationstherapie des BRAF-Inhibitors Encorafenib und des Anti-EGFR-Antikörpers Cetuximab steht eine chemotherapiefreie, zielgerichtete Doppelblockade nun für die Routineversorgung zur Verfügung. Die Zulassung der Kombination gilt für Patienten mit einem mKRK mit $B R A F^{V 600 E_{-}}$ Mutation, die zuvor eine systemische Vortherapie erhalten haben [43].

Die der Zulassung zugrunde liegende Phase-III-Studie BEACON CRC untersuchte die Dreifachblockade aus Encorafenib und Cetuximab plus dem MEK-Inhibitor Binimetinib und der Zweifachblockade aus Encorafenib und Cetuximab im Vergleich zu einer Kontrolltherapie aus Irinotecan-basierter Chemotherapie plus Cetuximab in Patienten mit BRAFV600E-mutiertem mKRK, die zuvor 1 oder 2 palliative Therapielinien erhalten hatten (• Abb. 2; [44]). 


\section{Phase II (palliativ nicht vorbehandeltes BRAF-mut. mKRK): Studiendesign ANCHOR ${ }^{\text {CRC }}$}

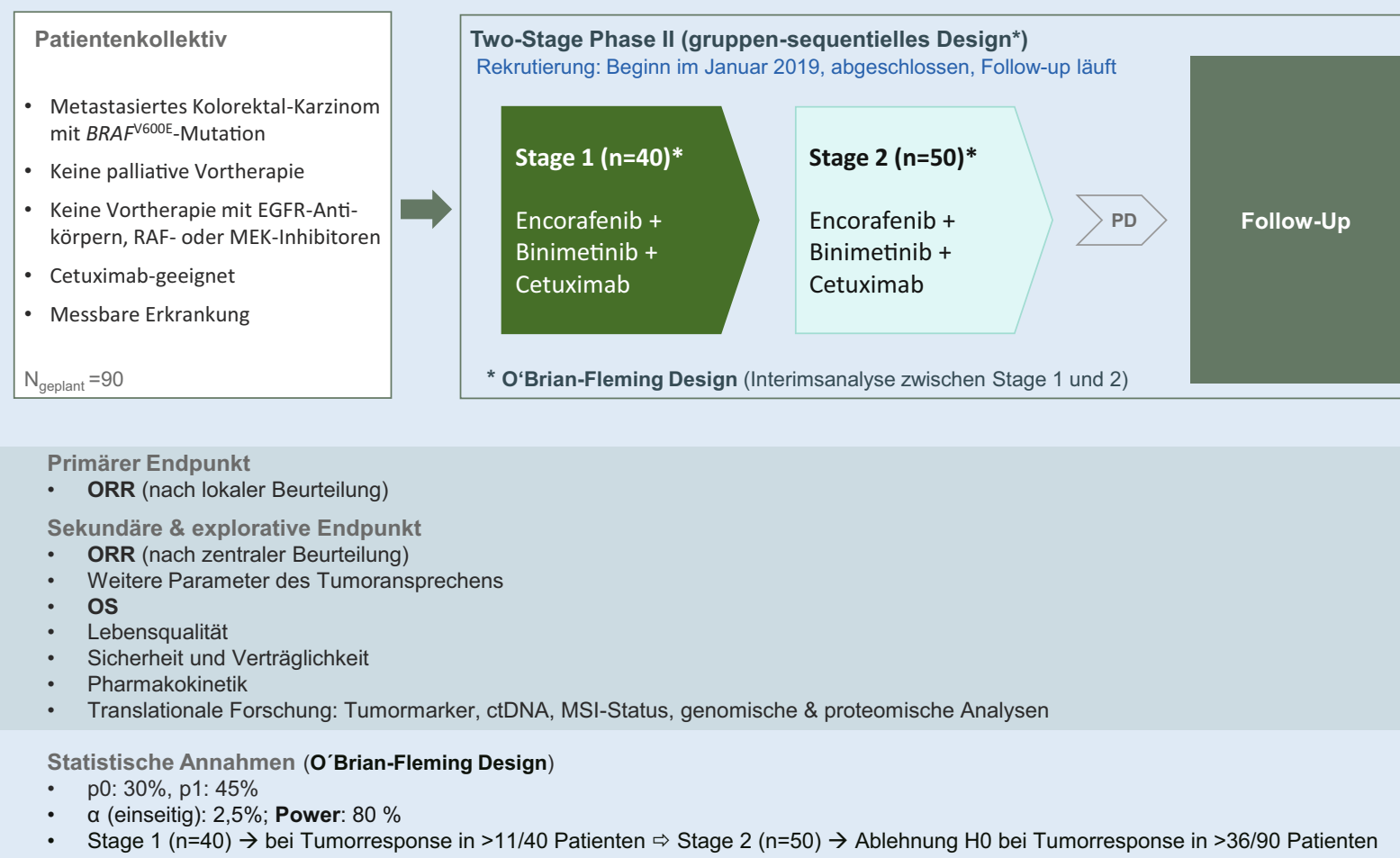

Abb. $3 \Delta$ Design der Phase-II-Studie ANCHOR bei Patienten mit einem nicht vorbehandeltem metastasierten kolorektalen Karzinom (mKRK) und BRAF ${ }^{V 600 E}$-Mutation. ORR Gesamtansprechrate, OS Gesamtüberleben, PD Progression

Primäre Endpunkte waren Tumoransprechen (ORR) und Gesamtüberleben (OS) der Dreifachblockade vs. Kontrolltherapie. Die Studie war auf den Endpunkt OS (für Therapiegruppe „Zweifachblockade“ versus Kontrollgruppe) hin gepowert. Weitere sekundäre Endpunkte (OS, ORR und progressionsfreie Überleben [PFS] - jeweils Zweifachblockade vs. Kontrolltherapie sowie das PFS der Dreifachblockade $v s$. Kontrolle) waren ebenfalls alpha-kontrolliert und somit von konfirmatorischer Relevanz. Insgesamt wurden 665 Patienten im Verhältnis $1: 1: 1$ in die 3 Therapiearme randomisiert.

Die primären Endpunkte der Studie wurden erreicht. Die Kombination aus Encorafenib, Cetuximab und Binimetinib zeigte in der primären Analyse (medianes OS-Follow-up 7,8 Monate) eine ORR von $26 \%$ [95\%-KI 18-35] vs. $2 \%[95 \%-\mathrm{KI}<1-7]$ unter der Kontrolltherapie $(p<0,001)$. Das mediane OS der Dreifachblockade gegenüber der Kontrolle betrug 9,0 vs. 5,4 Monate (HR
[95\%-KI]: 0,52 [0, 39-0,70]; $p<0,001)$ [44]. Für den alpha-kontrollierten Vergleich von OS der Zweifachblockade vs. Kontrolltherapie konnte für Encorafenib plus Cetuximab eine Verlängerung des medianen OS um 3 Monate $(8,4$ vs. 5,4 Monate; HR [95\%-KI]: 0,60 [0, 45-0,79], $p<0,001)$ gezeigt werden; die ORR betrug $20 \%$ (95\%-KI: 13-29) vs. $2 \%$ (95\%-KI: $<1-7 ; p<0,001)$.

Die Verträglichkeit der Zweifachblockade stellte sich gegenüber der Dreifachblockade sowie gegenüber der Kontrolle etwas günstiger dar (• Abb. 2). Das Sicherheitsprofil der Kombination aus Encorafenib und Cetuximab war gut handhabbar und zeigte die erwartbaren klassentypischen Ereignisse. Die am häufigsten beobachteten unerwünschten Ereignisse (UE) waren: erhöhtes Kreatinin (50\%), Übelkeit (34\%), Diarrhoe (33\%), verringertes Hämoglobin (32\%), Fatigue (30\%), akneiforme Dermatitis (29\%) und verminderter Appetit (27\%) [44].
Aufgrund der vergleichbaren Wirksamkeitsergebnisse der Dreifach- gegenüber der Zweifachblockade bei etwas günstiger Verträglichkeit von Encorafenib + Cetuximab sprach die Europäische Arzneimittelbehörde EMA im Juni 2020 die Zulassung für die Zweifachkombination aus [43].

Eine aktuelle Updateanalyse nach einem medianen Follow-up von 12,8 Monaten bestätigte die oben genannten Ergebnisse bei weitgehend unverändertem Verträglichkeitsprofil [45]. Das mediane Gesamtüberleben betrug hierbei 9,3 Monate (95\%-KI: 8,2-10,8) unter Dreifachblockade, 9,3 Monate bei Behandlung mit der nun neu zugelassenen Zweifachblockade aus Encorafenib und Cetuximab (95\%-KI: 8,0-11,3) sowie 5,9 Monate $(95 \%-\mathrm{KI}: 5,1-7,1)$ in der Kontrollgruppe.

Die zielgerichtete Dreifachblockade aus Encorafenib, Cetuximab und Binimetinib wird derzeit im Rahmen der zweistufigen ANCHOR CRC Phase- 


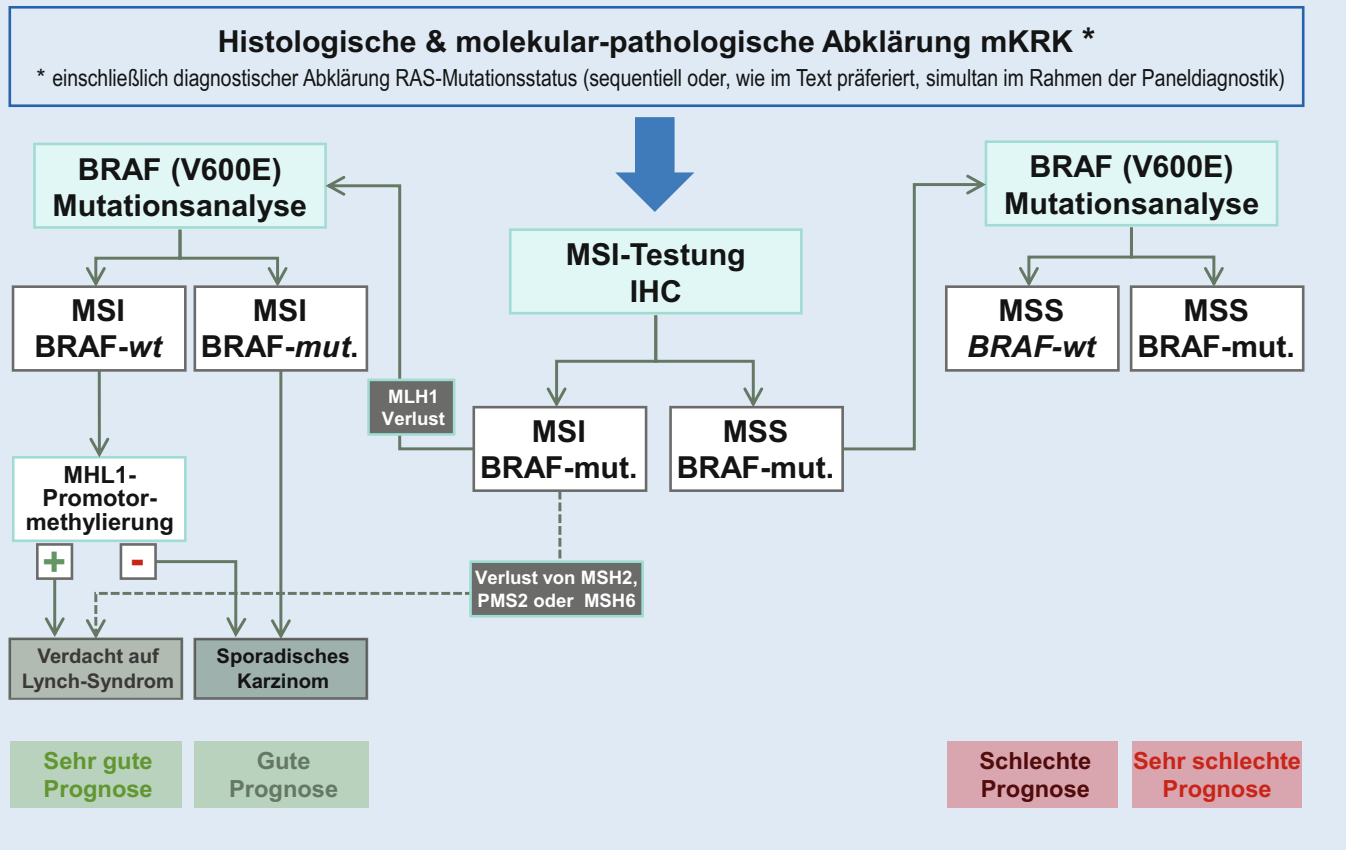

Abb. $4<$ Diagnostischer Algorithmus MSI-H/MSS - BRAF-MLH1-Promotormethylierung (bei/nach Ausschluss einer RAS-Mutation [3]; prognostische Angaben gemäß Lochhead et al. [17]). BRAF "rapidly accelerated fibrosarcoma isoform B", MLH1, MSH2, MSH6, PMS2 DNA-Reparaturenzyme/-Komplexe, MSI-H Mikrosatelliteninstabilität, MSS Mikrosatellitenstabilität, wt WildTyp
II-Studie als Erstlinientherapie weiter untersucht (• Abb. 3).

\section{BRAF-Diagnostik}

Aus der zuvor beschriebenen klinischen Situation ergibt sich die Notwendigkeit einer Testung auf das Vorliegen von RASund BRAF-Mutationen beim $\mathrm{mKRK}$, um eine an den Mutationsstatus angepasste Therapiesequenzplanung - im Fall $B R A F^{V 600 E}$-mutierter Patienten unter Berücksichtigung der neuen Therapieoption Encorafenib plus Cetuximab vornehmen zu können.

Die Leitlinien empfehlen eine solche Diagnostik vor der Einleitung der Erstlinientherapie des mKRK bzw. bereits bei der Erstdiagnose des KRK, um ggf. zusammen mit einer dMMR-Testung das Vorliegen eines Lynch-Syndroms ausschließen zu können [3, 4]. Solche hereditären KRK ohne Polyposis (HNPCC) stellen wie $B R A F$-mutierte Tumore einen biologisch unterschiedlichen Subtyp des KRK dar. Bei Vorliegen einer BRAF-Mutation in einem dMMR/MSI-H-Tumor kann ein Lynch-Syndrom weitestgehend ausgeschlossen werden. Die zeitgerechte Bestimmung des BRAF-Mutationsstatus ist somit von diagnostischer und insbesondere auch therapeutischer Relevanz (verzögerungsfreier Start der Erstlinie;
Planung der Therapiesequenz) und unterstützt zudem bei der diagnostisch wichtigen Unterscheidung, ob die Defekte der Mismatchreparatur somatischer oder genetischer Natur sind [46-48]. Die Annahme eines sporadischen Tumors und somit der Ausschluss von HNPCC/ Lynch-Syndrom kann durch Analyse der MLH1-Promotormethylierung unterstützt werden, da das Vorliegen einer solchen Methylierung die Diagnostik eines sporadischen MSI-H-Status zusätzlich absichert (• Abb.4). Die BRAFAnalytik kann entweder zeitgleich zur RAS-Analytik oder stufendiagnostisch nach Ausschluss einer RAS-Mutation erfolgen. Heutzutage empfiehlt sich allerdings erstere Vorgehensweise mittels entsprechender Genpaneldiagnostik unter Verwendung von fokussiertem Next Generation Sequencing (NGS).

\section{Probenvorbereitung}

Im Rahmen der klinischen Befundklärung werden Proben zumeist im Rahmen einer Darmspiegelung oder der operativen Entfernung des Primärtumors erhalten. Nach Fixierung in $10 \%$ neutral gepuffertem Formalin (4\% Formaldehyd) für 24-48 h und Einbettung in Paraffin sind die Proben nach Extraktion der DNA für die unter • Abb. 4 aufgeführten
Untersuchungen sehr gut geeignet. Für die molekulare Bestimmung des MSI-HStatus sollten auch gesunde, tumorferne Gewebeanteile asserviert und untersucht werden [4]. Im Falle von Gewebeproben mit einem geringen prozentualen Tumorzellanteil wird zur Anreicherung der Tumorzellen eine Makrodissektion vor der DNA-Extraktion angeraten.

\section{Molekularpathologische, DNA- analytische Verfahren}

Zur Bestimmung des $B R A F^{V 600 E}-\mathrm{Mu}$ tationsstatus stehen unterschiedliche Testmethoden mit verschiedener Spezifität und Sensitivität zur Verfügung. Mit klassischen Testverfahren (• Tab. 2) wie der Sanger-Sequenzierung lassen sich $99 \%$ aller Mutationen erkennen mit einer Spezifität von $100 \%$. Es muss jedoch darauf geachtet werden, dass ein Tumorzellanteil von $20-30 \%$ nicht unterschritten werden darf. Der Nachweis der $B R A F^{V 600 E}$-Mutation mittels High-Resolution-Melting(HRM)-Analyse oder Pyrosequenzierung ist sensitiver als die Sanger-Sequenzierung, sodass ein Tumorzellgehalt von etwa $10-15 \%$ (5\% Sensitivität) ausreichend erscheint $[49,50]$. Ähnliche Sensitivitäten weisen auch kommerzielle Tests wie ThxIDBRAF-Kit ${ }^{\circledR}$ (bioMérieux, Marcy-l’Étoile, 


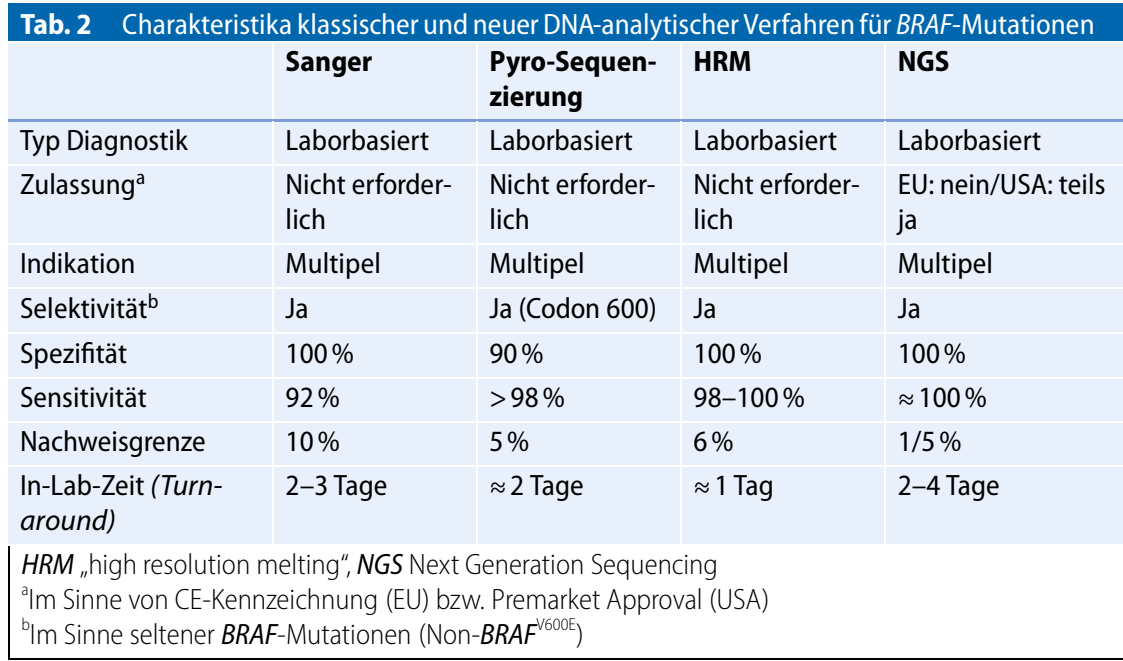

Frankreich;V600E sowie V600K), cobas $4800^{\circledR}$ BRAF Mutation Test (F. Hoffmann-La Roche AG, Basel, Schweiz; nur V600E) oder Idylla ${ }^{\mathrm{Ts}}$ BRAF Mutation Test (Biocartis NV, Mechelen, Belgien) auf (• Tab. 3; [51-53]).

In den letzten Jahren haben sich in der molekularen Diagnostik verstärkt NGSVerfahren durchgesetzt, mit denen sich eine Auswahl von diagnose- und therapierelevanten Genen/Genabschnitten („targeted NGS“) simultan mit hoher Sensitivität und Spezifität nachweisen lassen. Daher wird der Nachweis einer BRAF-Mutation beim KRK häufig nicht mehr als isolierter Einzelnachweis durchgeführt, sondern eingebettet in den parallelen Nachweis anderer molekularer Alterationen, wie zum Beispiel KRAS und NRAS. Die Sensitivität der NGS-basierten Verfahren ist grundsätzlich sehr hoch (etwa $1 \%$ ), wird aber durch Artefakte, die im Rahmen der Formalinfixierung entstehen, eingeschränkt. In vielen Laboren wird deshalb ein Schwellenwert von $5 \%$ Varianten-Allelfrequenz (VAF) vorgegeben, der unter bestimmten Bedingungen gegebenenfalls unterschritten werden kann $[49,50]$. Als NGS-Plattformen stehen heute primär ThermoFisher Scientific (Waltham, USA) und Illumina (San Diego, USA) zur Verfügung. Mit beiden Plattformen lassen sich zahlreiche kommerzielle oder eigene Genpanel einsetzen, wobei sowohl amplikonbasierte Verfahren (Multiplex-PCR) als auch Hybrid-Capture-Verfahren zur Anreicherung der gewählten Zielregionen infrage kommen. Für die Auswertung der NGS-Daten stehen zahlreiche bioinformatische Programme zur Verfügung, die allerdings durch in der molekularen Diagnostik sehr erfahrene Wissenschaftler/Ärzte verwendet werden sollten.

Im Rahmen der BEACON-CRC-Studie, die in insgesamt 221 Zentren in 28 Ländern durchgeführt wurde (davon 111 Zentren in Europa), ergab die Auswertung der für die BRAF-Bestimmung von 510 Proben eingesetzten Verfahren folgendes Bild: In 48,8\% der Untersuchungen wurden für die BRAFTestung noch immer Einzelgennachweise geführt. Proteinbasierte Verfahren (Immunhistologie) kamen in 0,7\% der Analysen zum Einsatz. Die Mehrheit der BRAF-Testungen wurde allerdings zusammen mit dem Nachweis weiterer Genveränderungen (z. B. als fokussierte, amplikonbasierte NGS) durchgeführt (50,5\%). Die zwischen lokaler und zentraler Testung beobachtete Abweichung zeigt dabei die Relevanz einer Standardisierung von diagnostischen Verfahren, insbesondere im Hinblick auf die zunehmende Bedeutung zielgerichteter Therapieansätze. Eine eindeutige Bestätigung der lokal nachgewiesenen $B R A F^{\mathrm{V} 600 \mathrm{E}_{-}}$ Mutation erfolgte lediglich in 90,7\%. Diese Diskrepanz basierte bemerkenswerterweise überwiegend auf einer ungenügenden Anzahl Tumorzellen in den Proben - aller Wahrscheinlichkeit nach aufgrund der Tatsache, dass die BRAFmutierten Tumore grundsätzlich mit einem muzinösen Adenokarzinom asso- ziiert sind, welches weniger Tumorzellen enthält. Bei 1,6\% der zentralen Wiederholungstests wurde das lokale Ergebnis eindeutig negiert. Diese Möglichkeit einer Diskonkordanz zwischen lokaler und zentraler Testung in Betracht ziehend erlaubte das Studienprotokoll zwar den Einschluss von Patienten basierend auf einem lokalen $B R A F^{\mathrm{V} 600 \mathrm{E}}$-Mutationsnachweis im Rahmen des molekularen Prescreenings, forderte als Einschlusskriterium aber zudem und binnen 30 Tagen nach erstmaligem Erhalt der Studienmedikation die zentrale Bestätigung. Nachdem die Studie die präspezifizierte Anzahl abweichender Testergebnisse erreicht hatte, wurde das Vorliegen des zentralen Nachweises durch den in den USA als Companion Diagnostic entwickelten Assay zur Voraussetzung für die Aufnahme aller weiterer Patienten.

Zwischen der Europäischen Union (EU) und den USA bestehen Unterschiede in der Regulierung von In-vitroDiagnostika (IVD). Solche Tests unterliegen in den USA einer zentralen Zulassung (Premarket Approval) durch die Food and Drug Administration (FDA), während in der EU eine dezentrale Zulassungsphilosophie vorherrscht, bei der die Hersteller die Konformität ihres Tests durch eine „Benannte Stelle“ („notified body“) bewerten lassen können und danach die sog. CEKennzeichnung („Conformité Européene") selbst auf dem Produkt bzw. Test aufbringen ${ }^{2}$. Des Weiteren erteilt die FDA Zulassungen für Arzneimittel bei den zielgerichteten Therapien häufig nur in Verbindung mit einem festgelegten und zeitgleich ebenfalls zugelassenen Companion Diagnostic, das zum Zulassungsbeginn häufig marktexklusiv für das entsprechende Arzneimittel ist. Die Verwendung des Companion Diagnostic ist somit Voraussetzung zur Verschreibung des Arzneimittels durch den Arzt [54].

\footnotetext{
2 Mit der CE-Kennzeichnung erklärt der Hersteller, Inverkehrbringer oder EU-Bevollmächtigte gemäßEU-Verordnung 765/2008, ,dass das Produkt den geltenden Anforderungen genügt, die in den Harmonisierungsrechtsvorschriften der Gemeinschaft über ihre Anbringung festgelegt sind".
} 


\begin{tabular}{|c|c|c|c|c|c|}
\hline & $\begin{array}{l}\text { THxID }{ }^{\circledR} \text { BRAF Kit } \\
\text { (bioMérieux, Marcy- } \\
\text { l'Étoile, Frankreich) }\end{array}$ & $\begin{array}{l}\text { cobas }^{\circledR} 4800 \text { BRAF V5600 } \\
\text { Mutation Test } \\
\text { (F. Hoffmann-La Roche AG, } \\
\text { Basel, Schweiz) }\end{array}$ & $\begin{array}{l}\text { Idylla }{ }^{\mathrm{Tm}} \text { BRAF Mutati- } \\
\text { on Test (Biocartis NV, } \\
\text { Mechelen, Belgien) }\end{array}$ & $\begin{array}{l}\text { Qiagen therascreen }{ }^{\circledR} \text { BRAF } \\
\text { V600E RGQ PCR kit } \\
\text { (Qiagen NV, Venlo, Nieder- } \\
\text { lande) }\end{array}$ & $\begin{array}{l}\text { Foundation One }{ }^{\circledR} \text { CDx } \\
\text { (Roche Pharma AG, } \\
\text { Grenzach-Wyhlen, } \\
\text { Deutschland) }\end{array}$ \\
\hline $\begin{array}{l}\text { Typ Dia- } \\
\text { gnostik }\end{array}$ & Standardisiert & Standardisiert & Standardisiert & Standardisiert & NGS \\
\hline Zulassung & USA (CDx), EU (CE) & USA (CDx), EU (CE) & USA (CDx), EU (CE) & USA (CDx), EU (CE) & USA (CCDx) \\
\hline $\begin{array}{l}\text { FDA PMA } \\
\mathrm{N}^{0} \text { (Jahr) }\end{array}$ & P120014 (2012) & P110020/S016 (2016) & $\begin{array}{l}\text { (510(k) Notifizierung } \\
\text { nicht erforderlich) }\end{array}$ & P190026 (2020) & P170019 (2017) \\
\hline Indikation & Melanom & Melanom & Multiple Indikationen & CRC & $\begin{array}{l}\text { Multiple Mutationen und } \\
\text { Indikationen }\end{array}$ \\
\hline $\begin{array}{l}\text { Selektivi- } \\
\text { tät }\end{array}$ & Nur V600E, V600K & Nur V600E & $\begin{array}{l}\text { V600E/E2/D und } \\
\text { V600K/R/M }\end{array}$ & Nur V600E & Nur V600E, V600K \\
\hline $\begin{array}{l}\text { Sensitivi- } \\
\text { tät }\end{array}$ & $\begin{array}{l}>96 \% \mathrm{~V}^{\mathrm{V} 600 \mathrm{E}} ;>92 \% \\
\text { V600K }\end{array}$ & $>98 \%$ & $>98 \%$ & $>98 \%$ & $100 \%$ \\
\hline Spezifität & $100 \%$ & $>98 \%$ & $>98 \%$ & $100 \%$ & $\approx 100 \%$ \\
\hline $\begin{array}{l}\text { Nachweis- } \\
\text { grenze }\end{array}$ & $5 \%$ V600E, $5 \%$ V600K & $5-7 \%{ }^{\mathrm{V} 600 \mathrm{E}},>35 \%$ V600K & Nicht spezifiziert & $8 \%$ & $2 \%$ \\
\hline $\begin{array}{l}\text { In-Lab- } \\
\text { Zeit (Turn- } \\
\text { around) }\end{array}$ & $1 \mathrm{Tag}$ & $1 \mathrm{Tag}$ & $2-4 \mathrm{~h}$ & 1 Tag & $\approx 3-5$ Tage \\
\hline
\end{tabular}

Die US-amerikanische Gesetzgebung unterscheidet solche standardisierten, zumeist kommerziell erhältlichen Tests von den "laboratory-developed tests“ (LDT), die - siehe dieklassischen Testverfahren - von Instituten in Eigennutzung konzipiert, validiert und angewendet werden. Seitens der Deutschen Akkreditierungsstelle (DAkkS) werden die LDT auch als In-house-Tests bezeichnet. Diese unterliegen in der Regel keiner Zulassung oder Kennzeichnungspflicht. Es gibt allerdings einen Leitfaden der DAkkS zur Validierung molekularpathologischer Untersuchungsverfahren $[55,56]$. In den USA gibt es seit Januar 2017 ein Positionspapier, in dem eine stärkere, prospektive Regulierung von LDT aufgrund der zunehmenden prognostischen und prädiktiven Bedeutung propagiert wird - dies gilt insbesondere auch für die Stellung und stetig wachsende Bedeutung des NGS [57, 58]. Mit dem FoundationOne ${ }^{\circledR}$ CDx (F1CDx) Test hat Ende 2017 erstmalig ein NGS-Verfahren in den USA eine Zulassung als Companion Diagnostic erhalten (• Tab. 3; [59]).

Vor diesem Hintergrund lässt sich die Vielfalt der konkurrierenden klassischen und neuen DNA-analytischen Verfah- ren zur BRAF-Mutationsbestimmung leichter einordnen. Von den kommerziellen, allelspezifische PCR-Techniken einsetzenden Verfahren ist in den USA derzeitig einzig der Qiagen therascreen ${ }^{\circledR}$ Test beim BRAF-mutierten mKRK empfohlen, in Europa liegt eine CE-Kennzeichnung vor. Es ist zu erwarten, dass es auch für die derzeitig nur beim Melanom zugelassenen Tests bald entsprechende Anpassungen in den USA geben wird, das KRK betreffend. In der BEACONCRC-Zulassungsstudie waren als Verfahren ausschließlich die PCR und NGS basierend auf lokalen Assays im Studienprotokoll erlaubt [44].

Ein Vergleich zwischen kommerziellen (d.h. FDA-zugelassenen) Tests und LDT führte für die EGFR-, KRAS- und $B R A F$-Testung zum Ergebnis, dass es in der Assayperformance keinen Gesamtunterschied zwischen den Methoden bezüglich der 3 untersuchten Gene gibt, die durchschnittliche Analysegenauigkeit betrug $97 \%$ [60]. Vor dem Hintergrund der zuvor für das KRK dargestellten Notwendigkeit zur Testung von KRAS, BRAF, MSI-H/dMMR, MLH1 und ggf. weiteren Genen steht in der pathologischen Praxis heute natürlich die Paneldiagnostik im Fokus - in Deutschland setzen alle universitären und große nichtuniversitären Einrichtungen dafür mittlerweile fokussiertes NGS ein. Hierbei kommen als Plattformen häufig die Systeme von Illumina (MiSeq $^{\mathrm{mm}}$ oder NextSeq ${ }^{\mathrm{Tx}}$ ) und Thermo Fisher (Ion Gene Studio S5 ${ }^{\text {TM }}$ ) zum Einsatz [61-63]. Im Rahmen einer deutschlandweiten multizentrische Validierungsstudie konnte eine hohe Überstimmung zwischen verschiedenen NGS-Plattformen und Genpanels gezeigt werden. Getestet wurden neben dem KRK auch Proben von Lungen- und Mammakarzinomen [61].

\section{Immunhistochemische Verfahren}

Neben den DNA-analytischen Verfahren stellen proteinbasierte Analysen unter Verwendung des VE1-Antikörpers eine Alternative dar zur molekularpathologischen Testung von $B R A F^{V 600 E}$. Letztere gilt weithin als der Goldstandard bei der BRAF-Mutationstestung [50, 64]. Zugleich aber ist der proteinbasierte immunhistologische Nachweis, der auch bei der MSI-Testung Einsatz finden kann, die einzige sinnvoll praktizierbare Methode zur Bestimmung der Expression mutanten BRAF-Proteins. Die Spezifität des 
Verfahrens liegt bei 98-100\%, die Sensitivität bei $85-100 \%[49,50]$, die In-LabTurnaround-Zeit einen Tag. Die Verlässlichkeit der Methode ist somit grundlegend gegeben, allerdings bleiben einige Herausforderungen, wie zum Beispiel die Etablierung eines verlässlichen Scorings der Proteinexpression [64]. Die Bestimmung der Immunfärbung zur Bestimmung BRAF-mutierten Proteins bietet sich somit zwar als schneller und kostengünstiger Test an, jedoch ist beim mKRK mittlerweile die Bestimmung multipler Alterationen erforderlich, sodass DNAanalytische Verfahren heutzutage sicherlich bevorzugt zur Anwendung kommen sollten.

Chu et al. untersuchten populationsbasiert die Ergebnisse der immunhistochemischen Testung (IHC) und NGSTestung (BRAF ${ }^{\mathrm{V} 600 \mathrm{E}}$ ) [65]. Die Rate falsch positiver IHC-Tests betrug $17 \%$, wobei nur $43 \%$ aller IHC-getesteten Patienten per NGS überprüft wurden. NGS-getestete Patienten hatten ein besseres medianes OS bei jüngerem Alter, geringerer Rate synchroner Metastasen und höherer Therapierate. Die Autoren kamen zu dem Schluss, dass NGS zwar die Standardtestung sein sollte, sollte NGS jedoch nicht unmittelbar zeitnah zugänglich sein, stellt die IHC einen sinnvollen Screeningtest mit rascher Ergebnisverfügbarkeit dar, zumal mittels reflexiver IHC-Testung $57 \%$ mehr BRAF-mutierte mKRK identifiziert werden konnten als durch Standard-NGS-Einsatz.

\section{Fazit für die Praxis}

- Der Nachweis einer BRAF ${ }^{V 600 E}$-Mutation ist insbesondere vor dem Hintergrund einer Mikrosatellitenstabilität (MSS) mit einer sehr schlechten Prognose assoziiert und stellt somit einen aggressiven Subtyp des kolorektalen Karzinoms (KRK) dar.

- Patienten mit BRAF ${ }^{V 600 E}$-mutiertem metastasiertem KRK (mKRK) weisen somit einen hohen „unmet medical need" auf. Mit Encorafenib + Cetuximab steht nunmehr ein chemotherapiefreier, zielgerichteter Therapiestandard in der Zweitund Drittlinie zur Verfügung. Die Aufnahme der kombinierten BRAF- und EGFR-Blockade in die deutschen/ europäischen Behandlungsalgorithmen und Guidelines ist in den kommenden Monaten zu erwarten.

- Im Sinne einer adäquaten Planung der Therapiesequenz ist daher bei allen Patienten mit einem mKRK vor Einleitung der Erstlinientherapie eine BRAF-Testung unbedingt erforderlich.

- Für die Testung stehen eine Vielzahl von Methoden zur Verfügung, wobei die Paneldiagnostik mit Next Generation Sequencing - insbesondere in Kombination mit dem Nachweis von weiteren molekularen Alterationen bevorzugt zur Anwendung kommen sollte.

\section{Korrespondenzadresse}

\section{Prof. Dr. Michael Hummel}

Institut für Pathologie, Campus Charité Mitte, Charité - Universitätsmedizin Berlin

Virchowweg 16/17a, 10117 Berlin, Deutschland michael.hummel@charite.de

Förderung. Eine finanzielle Unterstützung dieser Arbeit erfolgte in Form redaktionellen und editoriellen Supports (Dr. Markus Hartmann, Ecc-Oncology, Trier, Deutschland) durch die Pierre Fabre Pharma $\mathrm{GmbH}$.

Funding. Open Access funding enabled and organized by Projekt DEAL.

\section{Einhaltung ethischer Richtlinien}

Interessenkonflikt. A. Vogel hat, ohne Zusammenhang mit der hier dargestellten Arbeit, in den vorausgegangenen 3 Jahren Honorare erhalten von den Firmen Bristol-Myers Squibb, Merck, MSD, Pierre Fabre Pharma und Roche. M. Hummel erhielt von Novartis, BMS, MSD and Pierre Fabre finanzielle Unterstützung für Vorträg bzw. Beratung. S. Hegewisch-Becker und J. Neumann geben an, dass kein Interessenkonflikt besteht.

Für diesen Beitrag wurden von den Autoren keine Studien an Menschen oder Tieren durchgeführt. Für die aufgeführten Studien gelten die jeweils dort angegebenen ethischen Richtlinien.

Open Access. Dieser Artikel wird unter der Creative Commons Namensnennung 4.0 International Lizenz veröffentlicht, welche die Nutzung, Vervielfältigung, Bearbeitung, Verbreitung und Wiedergabe in jeglichem Medium und Format erlaubt, sofern Sie den/die ursprünglichen Autor(en) und die Quelle ordnungsgemäßnennen, einen Link zur Creative Commons Lizenz beifügen und angeben, ob Änderungen vorgenommen wurden.
Die in diesem Artikel enthaltenen Bilder und sonstiges Drittmaterial unterliegen ebenfalls der genannten Creative Commons Lizenz, sofern sich aus der Abbildungslegende nichts anderes ergibt. Sofern das betreffende Material nicht unter der genannten Creative Commons Lizenz steht und die betreffende Handlung nicht nach gesetzlichen Vorschriften erlaubt ist, ist für die oben aufgeführten Weiterverwendungen des Materials die Einwilligung des jeweiligen Rechteinhabers einzuholen.

Weitere Details zur Lizenz entnehmen Sie bitte der Lizenzinformation auf http://creativecommons.org/ licenses/by/4.0/deed.de.

\section{Literatur}

1. Ferlay J, Colombet M, Soerjomataram I et al (2018) Cancer incidence and mortality patterns in Europe: estimates for 40 countries and 25 major cancers in 2018. Eur J Cancer 103:356-387

2. Dienstmann R, Salazar R, Tabernero J (2018) Molecular subtypes and the evolution of treatment decisions in metastatic colorectal cancer. Am Soc Clin Oncol Educ Book 38:231-238

3. Leitlinienprogramm Onkologie (Deutsche Krebsgesellschaft, Deutsche Krebshilfe, AWMF) (2019) S3-Leitlinie Kolorektales Karzinom, Langversion 2.1. http://www.leitlinienprogramm-onkologie. de/leitlinien/kolorektales-karzinom/. Zugegriffen: 20. Mai 2020 (AWMF Registrierungsnummer: 021/007OL)

4. Cervantes A, Adam R, Sobrero A et al (2016) ESMO consensus guidelines for the management of patients with metastatic colorectal cancer. Ann Oncol 27:1386-1422

5. Dankner M, Rose AAN, Rajkumar S et al (2018) Classifying BRAF alterations in cancer: new rational therapeutic strategies for actionable mutations. Oncogene 37:3183-3199

6. Sanz-Garcia E, Argiles G, Elez E et al (2017) BRAF mutant colorectal cancer: prognosis, treatment, and new perspectives. Ann Oncol 28:2648-2657

7. Cancer Genome Atlas Network (2012) Comprehensive molecular characterization of human colon and rectal cancer. Nature 487:330-337

8. Davies H, Bignell GR, Cox C et al (2002) Mutations of the BRAF gene in human cancer. Nature 417:949-954

9. Tannapfel A, Neid M, Aust D et al (2010) The origins of colorectal carcinoma: specific nomenclature for different pathways and precursor lesions. Dtsch Arztebl Int 107:760-766

10. Baretton GB, Tannapfel A, Schmitt W (2011) Standardized and structured histopathological evaluation of colorectal polyps: a practical checklist against the background of the new WHO classification. Pathologe 32:289-296

11. Bylsma LC, Gillezeau C, Garawin TA et al (2020) Prevalence of RAS and BRAF mutations in metastatic colorectal cancer patients by tumor sidedness: a systematic review and meta-analysis. CancerMed 9:1044-1057

12. Tran B, Kopetz S, Tie J et al (2011) Impact of BRAF mutation and microsatellite instability on the pattern of metastatic spread and prognosis in metastatic colorectal cancer. Cancer 117:4623-4632

13. Roth AD, Tejpar S, Delorenzi M et al (2010) Prognostic role of KRAS and BRAF in stage II and III resected colon cancer: results of the translational study on the PETACC-3, EORTC 40993, SAKK 60-00 trial.J Clin Oncol 28:466-474 
14. Safaee Ardekani G, Jafarnejad SM, Tan L et al (2012) The prognostic value of BRAF mutation in colorectal cancer and melanoma: a systematic review and meta-analysis. PLoSOne 7:e47054

15. Taieb J, Lapeyre-Prost A, Laurent Puig P et al (2019) Exploring the best treatment options for BRAF-mutant metastatic colon cancer. Br J Cancer 121:434-442

16. Venderbosch S, Nagtegaal ID, Maughan TS et al (2014) Mismatch repair status and BRAF mutation status in metastatic colorectal cancer patients: a pooled analysis of the CAIRO, CAIRO2, COIN, and FOCUS studies. Clin Cancer Res 20:5322-5330

17. Lochhead P, Kuchiba A, Imamura $Y$ et al (2013) Microsatellite instability and BRAF mutation testing in colorectal cancer prognostication. J Natl Cancer Inst 105:1151-1156

18. Taieb J, Shi Q, Pederson L et al (2019) Prognosis of microsatellite instability and/or mismatch repair deficiency stage III colon cancer patients after disease recurrence following adjuvant treatment: results of an ACCENT pooled analysis of seven studies. Ann Oncol 30:1466-1471

19. Lee S, Cho NY, Choi Met al (2008) Clinicopathological features of $\mathrm{CpG}$ island methylator phenotypepositive colorectal cancer and its adverse prognosis in relation to KRAS/BRAF mutation. Pathol Int 58:104-113

20. Samowitz WS, Sweeney C, Herrick J et al (2005) Poor survival associated with the BRAF V600E mutation in microsatellite-stable colon cancers. Cancer Res 65:6063-6069

21. Sahin IH, Kazmi SM, Yorio JT et al (2013) Rare though not mutually exclusive: a report of three cases of concomitant KRAS and BRAF mutation and a review of the literature. J Cancer 4:320-322

22. Morris V, Overman MJ, JiangZQ etal (2014) Progression-free survival remains poor over sequential lines of systemic therapy in patients with BRAFmutated colorectal cancer. Clin Colorectal Cancer 13:164-171

23. Ulivi P, Capelli L, Valgiusti M et al (2012) Predictive role of multiple gene alterations in response to cetuximab in metastatic colorectal cancer: a single center study. J Transl Med 10:87

24. Pietrantonio F, Petrelli F, Coinu A et al (2015) Predictive role of BRAF mutations in patients with advanced colorectal cancer receiving cetuximab and panitumumab: a meta-analysis. Eur J Cancer 51:587-594

25. Rowland A, Dias MM, Wiese MD et al (2015) Meta-analysis of BRAF mutation as a predictive biomarker of benefit from anti-EGFR monoclonal antibody therapy for RAS wild-type metastatic colorectal cancer. Br JCancer 112:1888-1894

26. Modest DP, Martens UM, Riera-Knorrenschild J et al (2019) Folfoxiri plus panitumumab as first-line treatment of RAS wild-type metastatic colorectal cancer: the randomized, open-label, phase II Volfi study (AIO KRK0109). JClin Oncol 35:3401-3411

27. Loupakis F, Cremolini C, Salvatore L et al (2014) Folfoxiri plus bevacizumab as first-line treatment in BRAF mutant metastatic colorectal cancer. Eur J Cancer 50:57-63

28. Cremolini C, Loupakis F, Antoniotti C et al (2015) Folfoxiri plus bevacizumab versus folfiri plus bevacizumab as first-line treatment of patients with metastatic colorectal cancer: updated overall survival and molecular subgroup analyses of the open-label, phase 3 TRIBE study. Lancet Oncol 16:1306-1315

29. Cremolini C, Antoniotti C, Lonardi S et al (2019) Updated results of TRIBE2, a phase III, randomized strategy study by GONO in the first- and second- line treatment of unresectable mCRC. J Clin Onco 37(15):3508

30. Cremolini C, Antoniotti C, Stein A et al (2020) Folfoxiri/bevacizumab (bev) versus doublets/bev as initial therapy of unresectable metastatic colorectal cancer (mCRC): a meta-analysis of individual patient data (IPD) from five randomized trials. J Clin Oncol 38(15):4015

31. Karapetis CS, Liu H, Sorich M et al (2020) Impact of molecular markers status on treatment effects comparing EGFR and VEGF monoclonal antibodies (mAbs) in untreated metastatic colorectal cancer (mCRC): Pooled individual patient data (IPD) analysis of randomized trials from the ARCAD database. Ann Oncol 31(4):S426 (Abstr. 434P)

32. Kopetz S, Desai J, Chan E et al (2015) Phase II pilot study of vemurafenib in patients with metastatic BRAF-mutated colorectal cancer. J Clin Oncol 33:4032-4038

33. Prahallad A, Sun C, Huang $S$ et al (2012) Unresponsiveness of colon cancer to BRAF(V600E) inhibition through feedback activation of EGFR. Nature 483:100-103

34. Corcoran RB, Ebi H, Turke AB et al (2012) EGFR-mediated re-activation of MAPK signaling contributes to insensitivity of BRAF mutant colorectal cancers to RAF inhibition with vemurafenib. Cancer Discov 2:227-235

35. Poulikakos PI, Zhang C, Bollag G et al (2010) RAF inhibitors transactivate RAF dimers and ERK signalling in cells with wild-type BRAF. Nature 464:427-430

36. Bokemeyer C, Van Cutsem E, Rougier $P$ et al (2012) Addition of cetuximab to chemotherapy as first-line treatment for KRAS wild-type metastatic colorectal cancer: pooled analysis of the crystal and opus randomised clinical trials. Eur J Cancer 48:1466-1475

37. Douillard JY, Oliner KS, Siena S et al (2013) Panitumumab-Folfox4 treatment and RAS mutations in colorectal cancer. N Engl J Med 369:1023-1034

38. Stintzing S, Miller-Phillips L, Modest DP et al (2017) Impact of BRAF and RAS mutations on first-line efficacy of folfiri plus cetuximab versus folfiri plus bevacizumab: analysis of the FIRE-3 (AIO KRK0306) study. Eur J Cancer 79:50-60

39. Peeters M, Smith Oliner K, Price TJ et al (2014) Updated analysis of KRAS/NRAS and BRAF mutations in study 20050181 of panitumumab (pmab) plus folfiri for second-line treatment (tx) of metastatic colorectal cancer (mCRC). J Clin Oncol 32(5):3568

40. Seymour MT, Brown SR, Middleton $G$ et al (2013) Panitumumab and irinotecan versus irinotecan alone for patients with KRAS wild-type fluorouracil-resistant advanced colorectal cancer (Piccolo): a prospectively stratified randomised trial. Lancet Oncol 14:749-759

41. Peeters M, Oliner KS, Parker A et al (2013) Massively parallel tumor multigene sequencing to evaluate response to panitumumab in a randomized phase III study of metastatic colorectal cancer. Clin Cancer Res 19:1902-1912

42. Karapetis CS, Jonker D, Daneshmand M et al (2014) PIK3CA, BRAF, and PTEN status and benefit from cetuximab in the treatment of advanced colorectal cancer-results from NCIC CTG/AGITG CO.17. Clin Cancer Res 20:744-753

43. European Commission (2020) Zusammenfassung der Produkteigenschaften von Braftovi. https:// www.ema.europa.eu/en/documents/productinformation/braftovi-epar-product-information de.pdf.Zugegriffen:20. Aug. 2020
44. Kopetz S, Grothey A, Yaeger R et al (2019) Encorafenib, binimetinib, and cetuximab in BRAF V600E-mutated colorectal cancer. N Engl J Med 381:1632-1643

45. Kopetz S, Grothey A, Van Cutsem E et al (2020) Encorafenib plus cetuximab with or without binimetinib for BRAF V600E metastatic colorectal cancer: updated survival results from a randomized, three-arm, phase III study versus choice of either irinotecan or folfiri plus cetuximab (beacon CRC). J Clin Oncol 38(15):4001

46. Büttner R, Friedrichs N (2019) Hereditary colon cancer in Lynch syndrome/HNPCC syndrome in Germany. Pathologe 40:584-591

47. Rau TT, Dawson H, Hartmann A et al (2017) Hereditary colorectal cancer: an update on genetics and entities in terms of differential diagnosis. Pathologe 38:156-163

48. Bucksch K, Zachariae S, Aretz S et al (2020) Cancer risks in Lynch syndrome, Lynch-like syndrome, and familial colorectal cancer type $\mathrm{X}$ : a prospective cohort study. BMC Cancer 20:460

49. Ihle MA, Fassunke J, König K et al (2014) Comparison of high resolution melting analysis, pyrosequencing, next generation sequencing and immunohistochemistry to conventional Sanger sequencing for the detection of p.V600E and non-p.V600E BRAF mutations. BMC Cancer 14:13

50. Cheng L, Lopez-Beltran A, Massari F et al (2018) Molecular testing for BRAF mutations to inform melanoma treatment decisions: a move toward precision medicine. Mod Pathol 31:24-38

51. Marchant J, Mange A, Larrieux M et al (2014) Comparative evaluation of the new FDA approved THxIDTM-BRAF test with high resolution melting and sanger sequencing. BMC Cancer 14:519

52. Qu K, Pan Q, Zhang X et al (2013) Detection of BRAF V600 mutations in metastatic melanoma: comparison of the Cobas 4800 and Sanger sequencing assays. J Mol Diagn 15:790-795

53. Schiefer Al, Parlow L, Gabler L et al (2016) Multicenter evaluation of a novel automated rapid detection system of BRAF status in formalinfixed, paraffin-embedded tissues. J Mol Diagn 18:370-377

54. Jørgensen JT, Hersom M (2018) Clinical and regulatory aspects of companion diagnostic development in oncology. Clin Pharmacol Ther 103:999-1008

55. DAkkS (2016) Leitfaden des Sektorkomitees Pathologie/Neuropathologie für die Validierung von Untersuchungsverfahren in der Molekularpathologie. https://www.dakks.de/ sites/default/files/dokumente/71 sd 4037 leitfaden_validierung_molpath_20161004_v1.1. pdf. Zugegriffen: 30. Mai 2020

56. Dietmaier W, Hummel M (2018) Quality assurance in molecular pathology. Pathologe 39:178-180

57. FDA (2017) Discussion paper on laboratory developed tests (LDTs). https://www.fda.gov/ media/102367/download. Zugegriffen: 30. Mai 2020

58. Genzen JR (2019) Regulation of laboratorydeveloped tests. Am J Clin Pathol 152:122-131

59. FDA (2017) List of cleared or approved companion diagnostic devices (in vitro and imaging tools). https://www.fda.gov/medical-devices/ vitro-diagnostics/list-cleared-or-approvedcompanion-diagnostic-devices-vitro-andimaging-tools. Zugegriffen:30. Mai 2020

60. Kim AS, Bartley AN, Bridge JA et al (2018) Comparison of laboratory-developed tests and FDA-approved assays for BRAF, EGFR, and KRAS testing. JAMA Oncol 4:838-841 


\section{Übersichten}

61. Hirsch B, Endris V, Lassmann S et al (2018) Multicentervalidation of cancer gene panel-based next-generation sequencing for translational research and molecular diagnostics. Virchows Arch 472:557-565

62. Udar N, Lofton-Day C, Dong J et al (2018) Clinical validation of the next-generation sequencingbased extended RAS panel assay using metastatic colorectal cancer patient samples from the phase 3 prime study. J Cancer Res Clin Oncol 144:2001-2010

63. Kwon D, Kim B, Shin HC et al (2019) Cancer panel assay for precision oncology clinic: results from a 1 year study. TransI Oncol 12:1488-1495

64. Dvorak K, Higgins A, Palting J et al (2019) Immunohistochemistry with anti-BRAF V600E (VE1) mouse monoclonal antibody is a sensitive method for detection of the BRAF V600E mutation in colon cancer: evaluation of 120 cases with and without KRAS mutation and literature review. Pathol Oncol Res 25:349-359

65. Chu JE, Johnson B, Kugathasan L et al (2010) Population-based screening for BRAF V600E in metastatic colorectal cancer reveals increased prevalence and poor prognosis. Clin Cancer Res 26:4599-4605

\section{DEUTSCHER KREBSKONGRESS}

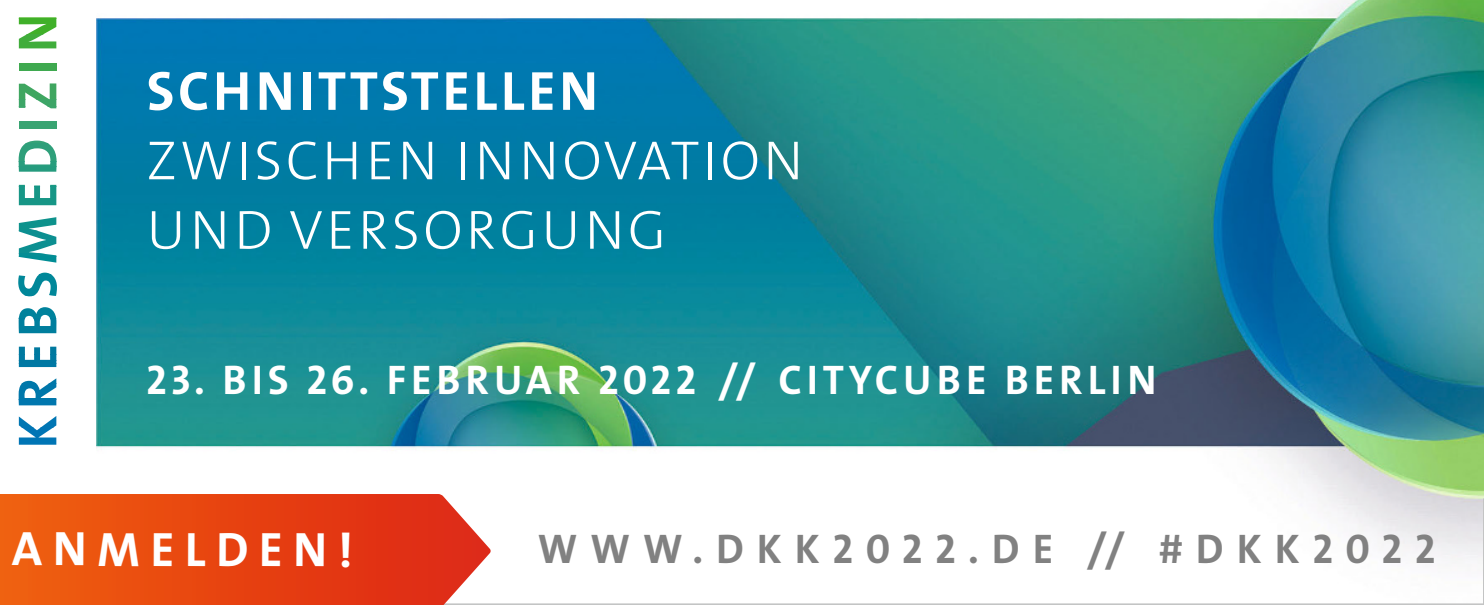

